reported, so the condition of the placenta after intrauterine surgery could not be determined. Additionally and more importantly in that study, fetal hyperphosphatemia was not described and, therefore, our results appear to be the first to describe fetal hyperphosphatemia after fetal Nx. There are no other published studies of the effect of fetal $\mathrm{Nx}$ on fetal mineral homeostasis.

Acknowledgment. Technical assistance was provided by $\mathrm{M}$. Ocampo and C. Mooers.

\section{REFERENCES}

1. MacDonald NS, Hutchinson DL, Helper M, Flynn E 1972 Movement of calcium in both directions across the primate placenta. Proc Soc Exp Bio Med 119:476 481

2. Pitkin RM 1975 Calcium metabolism in pregnancy: a review. Am J Obstet Gynecol 121:724-736

3. Kelly JJ, Sloan RE, Hoffman W, Sander C 1951 Accumulation of nitrogen and six minerals in the human fetus during gestation. Hum Biol 23:61-66

4. Ziegler EE, O'Donnel AM. Nelson SE, Foman SJ 1974 Body composition in the reference fetus. Anat $\mathrm{Rec}$ 179:1-8

5. Boass A, Toverud SU, McCain TA. Pike JW, Haussler MR 1977 Elevated serum levels of 1,25-dihydroxycholecalciferol in lactating rats. Nature 267:630-632

6. Pike JW, Parker JB, Haussler MR, Boass A, Toverud SU 1979 Dynamic changes in circulation 1.25-dihydroxyvitamin D during reproduction in rats. Science 204:1427-1429

7. Gray TK, Lester GE 1979 Evidence for extra-renal $1 \alpha$-hydroxylation of 25 hydroxyvitamin $D_{3}$ in pregnancy. Science 204:1311-1312

8. Tanaka Y, Bottalloran B. Schoes HK, DeLuca HF 1979 In vitro production of 1,25-dihydroxy-vitamin $D_{3}$ by rat by rat placental tissue. Proc Natl Acad Sci USA 76:5033-5035

9. Weisman Y, Harel A, Edelstein S, David M, Spirer Z, Golander A 1979 1,25dihydroxyvitamin $D_{3}$ and 24,25-dihydroxyvitamin $D_{3}$ in vitro synthesis by human decidua and placenta. Nature 281:317-319

10. Fenton E, Britton HT 1980 25-Hydroxycholecalciferol 1-hydroxylase activity in the kidney of fetal, neonatal and adult guinea pig. Biol Neonate 37:254-
256

11. Moore ES, deLannoy CW, Paton JB, Ocampo M 1972 Effect of $\mathrm{Na}_{2} \mathrm{SO}_{4}$ on urinary acidification in the fetal lamb. Am J Physiol 233:167-172

12. Fiske $\mathrm{CH}$, Subbarow YJ 1925 Measurement of inorganic phosphorus. J Eliol Chem 66:375-378

13. Schneider AS, Wells SA, Gunnells J, Leslie JB, Sherwood LM 1977 Regulation of function of transplanted parathyroid glands in man. Am J Med 63:7!10718

14. Nordin BEC, Peacock M 1969 Role of kidney in regulation of plasma calcium. Lancet 2:1280-1282

15. Moore ES, Chung E, Cevallos EE, McMann BJ 1978 Renal phosphate clearance in fetal lambs. Pediatr Res 12:1066-1069

16. Knox FG, Osswald $H$, Marchand GR, Spielman WS, Haas HA, Berndt T, Youngberg SP 1977 Phosphyate transport along the nephron. Am J Physiol 233:F261-F264

17. Thompson DD, Hiatt $\mathrm{HH} 1957$ Renal reabsorption of phosphate in normal human subjects and in patients with parathyroid disease. J Clin Invest 36.550-554

18. Smith FG Jr, Tinglof BO, Meuli J, Borden M 1969 Fetal response to parathyroid hormone in sheep. Am $J$ Physiol 27:276-280

19. Fuchs F, Fuchs A-R 1956 Studies on the placental transfer of phosphate in the guinea pig: I. The transfer from mother to fetus. Acta Physiol Scand 38:391397

20. Fuchs F, Fuchs A-R 1956 Studies on the placental transfer of phosphate in the guinea pig: II. The transfer from fetus to mother. Acta Physiol Scand 38:391397

21. Wilde WS, Cowie DB, Flexner LB 1946 Permeability of the placenta by the guinea pig to organic phosphate and its relation to fetal growth. Am J Physiol 147:360-366

22. Bruns ME, Fausto A, Avioli LV 1978 Placental calcium binding protein in rats. J Biol Chem 253:3186-3189

23. Wasserman RH, Taylor AN 1973 Intestinal absorption of phosphate in the chick. J Nutr 103:586-590

24. Ross R, Care AD, Robinson JS, Pickard DW, Weatherley AJ 1980 Perinatal 1,25-dihydroxycholecalciferol in the sheep and its role in the maintenance of the transplacental caicium gradient. J Endocrinol 87:17-18

25. Ross R, Care AD, Taylor CM. Pelc B, Sommerville BA 1979 The transplacental movement of metabolites of vitamin D in the sheep. In: Norman AW (ed) Vitamin D Basic Research and Its Clinical Application. Walter de Gruvter Publishers, Berlin, pp 241-242

\title{
Lung Surfactant Replacement in Premature Lambs with Extracted Lipids from Bovine Lung Lavage: Effects of Dose, Dispersion Technique, and Gestational Age
}

\author{
R. H. NOTTER, E. A. EGAN, M. S. KWONG, B. A. HOLM, AND D. L. SHAPIRO \\ Department of Pediatrics [R.H.N., B.H., D.L.S.], Division of Neonatology, University of Rochester, Rochester, \\ New York 14642 and Departments of Pediatrics [E.A.E., M.S.K.] and Physiology [E.A.E.], State University of
} New York at Buffalo, Buffalo, New York 14226

\begin{abstract}
Extracted bovine calf lung lipids (CLL) with minimal protein (approximately $1 \%$ ) were instilled prior to ventilation in groups of premature lambs of average gestational ages of 127 and 133 days. Aqueous dispersions of CLL were prepared by two techniques prior to instillation: sonication in an ice bath $(S)$ and mechanical vortexing at room temperature (V). A low surfactant dose (15 mg CLL/
\end{abstract}

Received October 3, 1984; February 12, 1985

Address for correspondence R.H Notter. Department of Pediatrics, Division of Neonatalogy, Box 777, University of Rochester, Rochester, NY 14642.

This study was supported by NIH Grants HL-25170, HL-22522, and HL-00945 (RCDA to RHN) and by Training Grant ES-07026 (to B.A.H.). $\mathrm{kg}$ animal weight) and a high dose $(100 \mathrm{mg} / \mathrm{kg})$ were investigated for each dispersion technique. Following tracheal instillation of surfactant, lambs were ventilated with $100 \%$ oxygen for $2 \mathrm{~h}$ with umbilical circulation intact, and for up to an additional $10 \mathrm{~h}$ after separation. A clear improvement in blood oxygenation and lung compliance was found over controls for lambs given $15 \mathrm{mg} / \mathrm{kg}$ and 100 $\mathrm{mg} / \mathrm{kg} \mathrm{CLL}(\mathrm{V})$, and $100 \mathrm{mg} / \mathrm{kg}$ CLL(S). Lambs treated with $15 \mathrm{mg} / \mathrm{kg}$ CLL(S) failed to improve over controls. Experimental groups treated with equal doses of CLL(V) and CLL(S) had similar amounts of lung lavage phospholipid, with values progressively declining during ventilation. 
Analyses of in vitro surface properties showed that both vortexed and sonicated CLL dispersions adsorbed to equilibrium surface pressures of $45-47$ dynes $/ \mathrm{cm}$ in seconds at concentrations $\geq 0.25 \mathrm{mg} \mathrm{CLL} / \mathrm{ml}$. Both dispersions also lowered surface tension to less than 1 dyne/cm under dynamic compression at $37^{\circ} \mathrm{C}$ in $100 \%$ humidity, although CLL(V) showed some enhancement over CLL(S) in dynamic surface activity at low subphase concentration $(0.5$ $\mathrm{mg} / \mathrm{ml}$ ). Moreover, CLL(V) and CLL(S) differed markedly in their effects on pressure-volume mechanics in a surfactant-deficient excised rat lung model. Instilled CLL(V) dispersions improved excised lung pressure-volume mechanics at significantly lower concentrations than CLL(S) dispersions. (Pediatr Res 19: 569-577, 1985)

\section{Abbreviations}

CLL, calf lung lipids

$\mathrm{V}, \mathrm{S}$, dispersion by vortexing; sonication

$\pi$, surface pressure

A-a $\mathrm{DO}_{2}$, alveolar-arterial oxygen difference

RDS, respiratory distress syndrome

P-V, pressure-volume

VEI, ventilator efficiency index

VP, volume pressure

The replacement of pulmonary surfactant in premature infants who develop the respiratory distress syndrome has been a subject of intense investigation since the early 1960's. Exogenous replacement mixtures studied have included natural surfactants obtained directly from lung lavage or amniotic liquid, organic solvent extracts of natural surfactant (supplemented or not with further additives), and a variety of artificial surfactants synthesized in the laboratory $(1-4)$. Natural surfactants from bronchoalveolar lavage have proven successful in surfactant replacement experiments in many species of premature animals over the past decade (eg, References 2-4), but extension to clinical use in humans confronts potential problems. One of these is the presence of significant amounts of protein in bronchoalveolar lavage surfactant (4-7), and possible adverse effects of instilling antigenic foreign protein into the lung. Another problem is retention of activity during sterilization, since the adsorption of natural surfactant is significantly retarded by heating (8).

Many of the drawbacks associated with the use of natural surfactant in replacement therapy are mitigated in lipid extracts from natural material. Although apoprotein acts to increase the adsorption of natural pulmonary surfactant (eg, References 4, 814), lipid extracts with almost an order of magnitude less protein can be formulated in vitro to exhibit the same rapid adsorption properties $(4,8,15-18)$. Such extracts have excellent dynamic surface tension lowering characteristics similar to natural lung surfactant $(15,17,18)$. When instilled into surfactant-deficient excised lungs (19) or into premature rabbit neonates $(4,20)$, extracts of bovine lung lavage surfactant with $1 \%$ protein have been shown to restore essentially normal P-V mechanics. In addition, Fujiwara and coworkers $(21-23)$ have reported similar biophysical and physiological results for related surfactant extracts with low protein content, supplemented with various additives including dipalmitoyl phosphatidylcholine.

One area in which lung surfactant extracts (as opposed to whole natural surfactant) have not had extensive study is in large animal physiological models of RDS such as premature lambs in vivo. In a previous study, we showed that surfactant replacement with extracted calf lung lipids (CLL, $1 \%$ protein) led to improved lung function in lambs of 130 days gestation compared to controls and to animals treated with an artificial surfactant, 7:3 dipalmitoyl phosphatidylcholine:egg-phosphatidylglycerol (17). The present paper is a more comprehensive evaluation of
CLL efficacy in premature lambs. The study involves groups of very immature lambs at an average gestation of 127 days, and groups of more developed (but still surfactant-deficient) lambs at 133 days gestation. The experiments also address exogenous surfactant dose effects, with tracheal instillation of 15 and 100 $\mathrm{mg} \mathrm{CLL} / \mathrm{kg}$ into lambs at both gestational ages. A final question studied is the effect of CLL dispersion methodology on physiological efficacy, since the surface properties of phospholipid mixtures can be a strong function of lipid dispersion method ( 8 , 16). CLL were thus dispersed by the common methods of sonication and mechanical vortexing, and these are shown to lead to dose-dependent differences in enhancing pulmonary function.

\section{MATERIALS AND METHODS}

Extracted lung lipids. Lungs were obtained from freshly sacrificed calves from the Conti Meat Packing Company, Rochester, NY, and mixed lipids were extracted as described previously $(8$, 17). The lungs, with trachea and bronchi intact, were lavaged with cold $0.15 \mathrm{M} \mathrm{NaCl}$, approximately 3-4 liters per lung given in four divided doses. The lavage fluid was centrifuged at $300 \times$ $g$ for $5 \mathrm{~min}$ to remove cellular debris; the supernatant was then drawn off and centrifuged at $12,000 \times g$ for $1 / 2 \mathrm{~h}$ to pellet the lipids. The pellet was resuspended in $0.15 \mathrm{M} \mathrm{NaCl}$ and the lipids extracted with chloroform-methanol (24). The final product was analyzed for phosphorus by the method of Chen et al. (25) and by thin-layer chromatography with the solvent system of Touchstone et al. (26). The CLL were found to be $94 \%$ phospholipid with a molar distribution of $83 \%$ phosphatidylcholine, $6 \%$ phosphatidylglycerol, $3 \%$ phosphatidylethanolamine, $5 \%$ phosphatidylinositol (+phosphatidylserine), and $2 \%$ sphingomyelin; a trace of lyso-phosphatidylcholine $(<1 \%)$ was present. The CLL contained $4 \%$ cholesterol and cholesterol esters; the protein content was approximately $1 \%$ by a modification of the method of Lowry et al. (27), which allowed analysis of protein in the presence of detergent. A second CLL preparation of similar composition (17) was used in experiments with three of the 35 surfactant-treated animals studied.

Lung surfactant replacement in lambs. Lambs were obtained from dated-pregnant ewes at two average gestational ages of 127 and 133 days (dating accuracy was within 1 day). Although separated by only a week in gestation, these two groups of lambs had quite different pulmonary maturity. The older group had immature lungs and surfactant deficiency by bubble stability testing (28) and phosphate analysis of fetal lung liquid $(<15 \mu \mathrm{mol}$ total lung). However, these older animals could be maintained for many hours with the ventilation protocol used (see below). By contrast, the younger group of lambs had total fetal lung fluid phosphates of $<1 \mu \mathrm{mol}$, and without exogenous surfactant could not be ventilated effectively for even a few hours after separation from the ewe. Evaluation of the efficacy of surfactant replacement in these two groups of lambs thus gives information useful for clinical applications where infants of widely varying pulmonary maturity are potential candidates for exogenous surfactant.

Premature lambs were exteriorized from ewes by hysterotomy, with the umbilical circulation maintained (17). The fetal trachea was cannulated, and an arterial catheter was placed in the carotid artery. Fetal lung liquid was aspirated, and a $10-15 \mathrm{ml}$ volume was removed and replaced with an equal volume of a $\mathrm{V}$ or $\mathrm{S}$ CLL dispersion (or saline in control experiments). Vortexing and probe sonication were chosen as representative of the two most common methods of dispersing phospholipids in water, ie, some kind of mechanical agitation (with or without particles such as glass beads) and some form of ultrasonic energy input. Details of the dispersion process are given below. CLL mixtures were instilled in a high dose of $100 \mathrm{mg} / \mathrm{kg}$ to approximate that commonly used in premature animal replacement studies with natural lung surfactant $(1,3,4)$. The low dose of $15 \mathrm{mg} / \mathrm{kg}$ was chosen arbitrarily to represent the probable range of marginal effectiveness, particularly for younger animals. The concentra- 
tion of instilled CLL dispersions for the high and low doses was 20 and $5 \mathrm{mg} \mathrm{CLL} / \mathrm{ml}$ saline, respectively. Experiments on lambs of different gestational ages were intermingled, as were experiments with different CLL doses and dispersion techniques.

Following CLL instillation, a 10-min pause was allowed for diffusive mixing with all endogenous lung lipid, and the premature lamb was then ventilated with $100 \%$ oxygen by means of a specially modified pressure cycled small animal respirator. Each lamb was ventilated for $2 \mathrm{~h}$ with the umbilical circulation intact, with blood gases monitored every $15 \mathrm{~min}$ and quasistatic P-V curves measured at 30 and $120 \mathrm{~min}$. The lamb was then separated from the ewe, and ventilation continued for up to $10 \mathrm{~h}$, at which point surviving animals were sacrificed. P-V inflation-deflation characteristics were again measured, and the lung was lavaged with $50 \mathrm{ml}$ of $0.15 \mathrm{M} \mathrm{NaCl}$ to obtain a final measure of alveolar phospholipid content. Inspired gas was uniform as $100 \% \mathrm{O}_{2}$ throughout all experiments. Maximum ventilator pressure settings were $30 / 6 \mathrm{~cm} \mathrm{H}_{2} \mathrm{O}$ for inspiratory/expiratory pressures, with a maximum frequency of 60 breaths per minute. These settings were decreased in some instances after the initial $90 \mathrm{~min}$ of ventilation if blood oxygenation permitted, as discussed below.

Index of ventilatory efficiency. The oxygenation of the blood in these experiments was measured by $\mathrm{PaO}_{2}$; because all animals were breathing $100 \%$ oxygen, virtually all hypoxemia represented shunting of venous blood and not ventilation/perfusion maldistributions. However, to reduce the threat of pneumothorax and the various physiological effects of hypocapnia, respirator pressures were lowered, if feasible, to try and attain a normal $\mathrm{pH}$ and $\mathrm{PaCO}_{2}$. Because ventilator input could vary from animal to animal, direct comparisons of $\mathrm{PaCO}_{2}$ between animals did not always reflect differences in lung function. For this reason, an index of ventilatory efficiency was developed. The tidal volume delivered by a given ventilator pressure difference (dynamic compliance) would be one measure of surfactant efficacy, but accurate prolonged measurement of tidal volume requires plethysmography when using continuous flow pressure-cycled ventilation. Instead, we calculated a semiempirical analog of dynamic compliance as an index of the effectiveness of mechanical ventilation in each animal.

A VEI which relates alveolar ventilation to respirator input, in the absence of spontaneous breathing, can be defined as:

$$
\mathrm{VEI}=\frac{\dot{\mathrm{V}}_{\mathrm{A}}}{\Delta \mathrm{P} \cdot \mathrm{f}}
$$

In equation (1), $\triangle \mathrm{P}$ is the difference between ventilator pressures at end inspiration and end expiration, $f$ is ventilator frequency, and $\dot{V}_{A}$ is alveolar ventilation. The alveolar ventilation can be calculated as the ratio of $\mathrm{CO}_{2}$ production to the mole fraction of alveolar $\mathrm{CO}_{2}$. If it is assumed that $\mathrm{CO}_{2}$ production in euthermic, resting lambs remains near normal minimal volumes of $5 \mathrm{ml}$ / $\mathrm{kg} / \mathrm{min}$, and that arterial $\mathrm{CO}_{2}$ tension approaches alveolar $\mathrm{CO}_{2}$, then alveolar ventilation is given by:

$$
\dot{\mathrm{V}}_{\mathrm{A}} \doteq \frac{3800}{\mathrm{PaCO}_{2}}
$$

In equation (2), $\mathrm{PaCO}_{2}$ is arterial carbon dioxide pressure (torr) and the constant 3800 is in units of $\mathrm{ml} \cdot$ torr $\cdot \mathrm{kg}^{-1} \mathrm{~min} \cdot{ }^{-1}$. Substitution of equation (2) into equation (1) gives VEI as:

$$
\mathrm{VEI}=\frac{3800}{\triangle \mathrm{P} \cdot \mathrm{f} \cdot \mathrm{PaCO}_{2}}
$$

The units of VEI in equation (3) are $\mathrm{ml} \cdot$ torr $^{-1} \cdot \mathrm{kg}^{-1}$ if ventilator excursion pressure is given in torr. The index allows comparison of respiratory status among animals whose ventilator pressures and $\mathrm{PaCO}_{2}$ values vary, and it also gives a useful measure of changes in lung function with time for individual animals. VEI is calculated in terms of easily accessible variables; as a dynamic compliance analog, it increases as pulmonary function improves.
General physiological measurements in lambs. General physiological measurement techniques were those described in detail by Egan et al. (17). Blood gases were measured on a Radiometer $\mathrm{ABL}$ II. A-a $\mathrm{DO}_{2}$ was calculated from the blood gas data and the alveolar air equation (29). Quasistatic P-V curves for premature lambs were determined by displacement of water from a buret; nitrogen was the gas used for inflation. For lamb P-V measurements, the chest was closed; these curves thus reflect lung plus thorax mechanics. Functional residual capacity was defined as the volume at zero distending pressure. Alveolar liquid volume

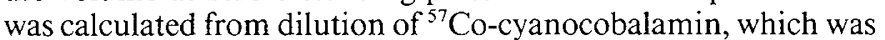
added to a measured aliquot of aspirated lung liquid and reinstilled into the lung prior to the start of ventilation. Total phospholipid content of alveolar liquid samples was measured by a standard phosphate assay (25).

Excised lung mechanical measurements. To help interpret data on the effects of CLL in lambs, additional physiological experiments were carried out in excised, surfactant-deficient rat lungs. In particular, the effects of different doses of vortexed and sonicated CLL dispersions on pulmonary P-V mechanics were measured as an independent measure of physiological efficacy.

Lungs were excised from adult rats (Sprague-Dawley, Charles Rivers Co., Wilmington, MA), and pulmonary P-V mechanics characterized in the surfactant-sufficient and surfactant-deficient states, as described by Bermel et al. (19). In brief, excised lungs were degassed, and a control VP deflation curve (quasistatic) was measured immediately at $37^{\circ} \mathrm{C}$ to define the surfactant-sufficient state. Leakage was checked by a stringent requirement for a stress relaxation rate less than $0.1 \mathrm{ml} / \mathrm{min}$ at a gas inflation pressure of $30 \mathrm{~cm} \mathrm{H} \mathrm{H}_{2} \mathrm{O}$ (total lung capacity for rat lung experiments). This requirement was also used as a standard for leak-free behavior for all subsequent VP curves in each set of lungs. The lungs were then made surfactant-deficient by a series of 10-15 lavages (19), degassed, and another VP deflation curve measured. This curve, compared to the initial surfactant-sufficient curve, had increasesd recoil pressures at all lung volumes less than $90 \%$ total lung capacity. After surfactant-sufficient and -deficient VP behavior was defined, a given amount of CLL(V) or CLL(S) in $2.5 \mathrm{ml}$ of $0.15 \mathrm{M} \mathrm{NaCl}$ was instilled into the deficient lung (infused in and out five times). The lungs were then degassed, and a VP deflation curve measured to determine the effect of the surfactant dispersion on lung mechanics. Only one instillation experiment was done per set of lungs.

Dynamic $\pi$-area measurements. Dynamic surface tension measurements were done on an oscillating bubble apparatus described in detail by Enhorning (30). This method involves the continuous monitoring of surface tension at the interface of a pulsating air bubble formed in an aqueous phase which contains dispersed surfactants. The bubble experiments were done at $37^{\circ}$ $\mathrm{C}$ and $100 \%$ humidity, with film subphases containing CLL initially dispersed by sonication or by vortexing. The volume of CLL dispersion used was $20 \mu \mathrm{l}$; concentrations of $0.5,1$, and 5 mg CLL per ml of $0.15 \mathrm{M} \mathrm{NaCl}$ were studied. Bubble cycling speed was 20 cycles per minute with an area decrease from 100 to $50 \%$. Dynamic surface tension lowering was monitored continuously, along with the time necessary to reach low minimum surface tension (surface tension $\min <2$ dynes $/ \mathrm{cm}$ ) after the start of bubble pulsation. In addition to bubble measurements, $\pi$-area isotherms and dynamic respreading behavior of solvent-spread CLL films (from hexane/ethanol spreading solvent, 9/1 v/v) were studied on a Wilhelmy surface balance (17) at a rate of 5 min per complete cycle.

Adsorption $\pi$-time experiments. Measurements of surface pressure-time adsorption were made at $35 \pm 2^{\circ} \mathrm{C}$ with a sandblasted Wilhelmy slide for CLL dispersed in a $0.15 \mathrm{M} \mathrm{NaCl}$ subphase, stirred continuously to remove diffusion resistance $(8,16)$. Adsorption was characterized for CLL dispersed by: 1) vortexing for $1 \mathrm{~h}$ at room temperature (V), and 2) sonication in an ice bath for 1-3 min (S). Vortexing was done with a Four Tube Vortex Mixer (Scientific Industries, Inc., Bohemia, NY) and sonication 
was with a microtip at a power of $25 \mathrm{~W}$ in a Heat Systems Sonicator, model W-220F. CLL was dried from chloroform under nitrogen to give a thin film in a test tube prior to addition of saline and dispersion by $\mathrm{V}$ or $\mathrm{S}$. Adsorption experiments were done on aliquots of dispersed CLL taken from the same preparations used in instillation experiments. Aliquots of lipid dispersions were added at time zero to $70 \mathrm{ml}$ stirred subphase to give final bulk phase concentrations of $0.06-0.25 \mathrm{mg}$ CLL per milliliter in adsorption studies.

Statistical methods. For continuous variables which were measured at discrete points, comparisons utilized the Student's $t$ test (two-tailed). This included data on blood gases, phospholipid content, and pulmonary mechanics in lambs. For sets of continuous excised lung $\mathrm{P}-\mathrm{V}$ curves, $t$ tests were done at specific points such as 30 and $70 \%$ of total lung capacity. In general, statistical significance in Tables 1 and 2 is expressed as $p<0.05$ or less as a combined indicator of results with a range of significance values below 0.05 .

\section{RESULTS}

Physiological results, 127-day gestation lambs. A total of 29 lambs was studied and divided into a control group and four experimental groups. The four experimental groups were given low or high doses $(15$ or $100 \mathrm{mg} / \mathrm{kg}$ ) of CLL dispersed by vortexing, CLL(V), or by sonication, CLL(S). The surfactant mixture was administered by intratracheal instillation and mixed with the fetal lung liquid as a single dose prior to the onset of ventilation. Table 1 gives an overall summary of the differences in blood oxygenation and pulmonary function found between experimental and control groups at 30 and $120 \mathrm{~min}$ after the start of ventilation, and at the end of each experiment. Major features of the results in Table 1 are as follows.

1) Control lambs (group I) exhibited clear signs and symptoms of severe lung disease, with high $\mathrm{A}-\mathrm{a} \mathrm{DO}_{2}$ and decreased functional residual capacity. All the animals died quickly after being severed from the maternal circulation.

2) Lambs given vortexed dispersions of CLL at low dose (group II) or high dose (group IV) showed clear improvement in lung function compared to controls. For low dose animals (15 $\mathrm{mg} / \mathrm{kg}$ ), the physiological effects were of similar magnitude to those found for high dose animals $(100 \mathrm{mg} / \mathrm{kg})$ in terms of both blood gases and pulmonary mechanics (Table 1). However, the lung function improvement was somewhat more variable at low dose; one of five low dose CLL(V) animals followed a course essentially equivalent to control lambs. Nonetheless, a significant beneficial response to low dose CLL(V) was present in the majority of animals, and this was not the case for a low dose of CLL(S) as noted below.

3) Lambs given sonicated dispersions of CLL at low dose (group III) did not exhibit improved lung function over controls for any of the five lambs studied. At high doses of $100 \mathrm{mg} / \mathrm{kg}$ of CLL(S) (group V), however, there was a significant improvement over controls in lung function, close to that seen with CLL(V) animals. ${ }^{1}$

${ }^{1}$ These high dose sonicated animals had a high incidence of pneumothorax compared to CLL(V) animals at the same dose, but the numbers are not sufficient to infer significance.

Table 1. Summary of blood gas and mechanical data for 127-day average gestation lambs*

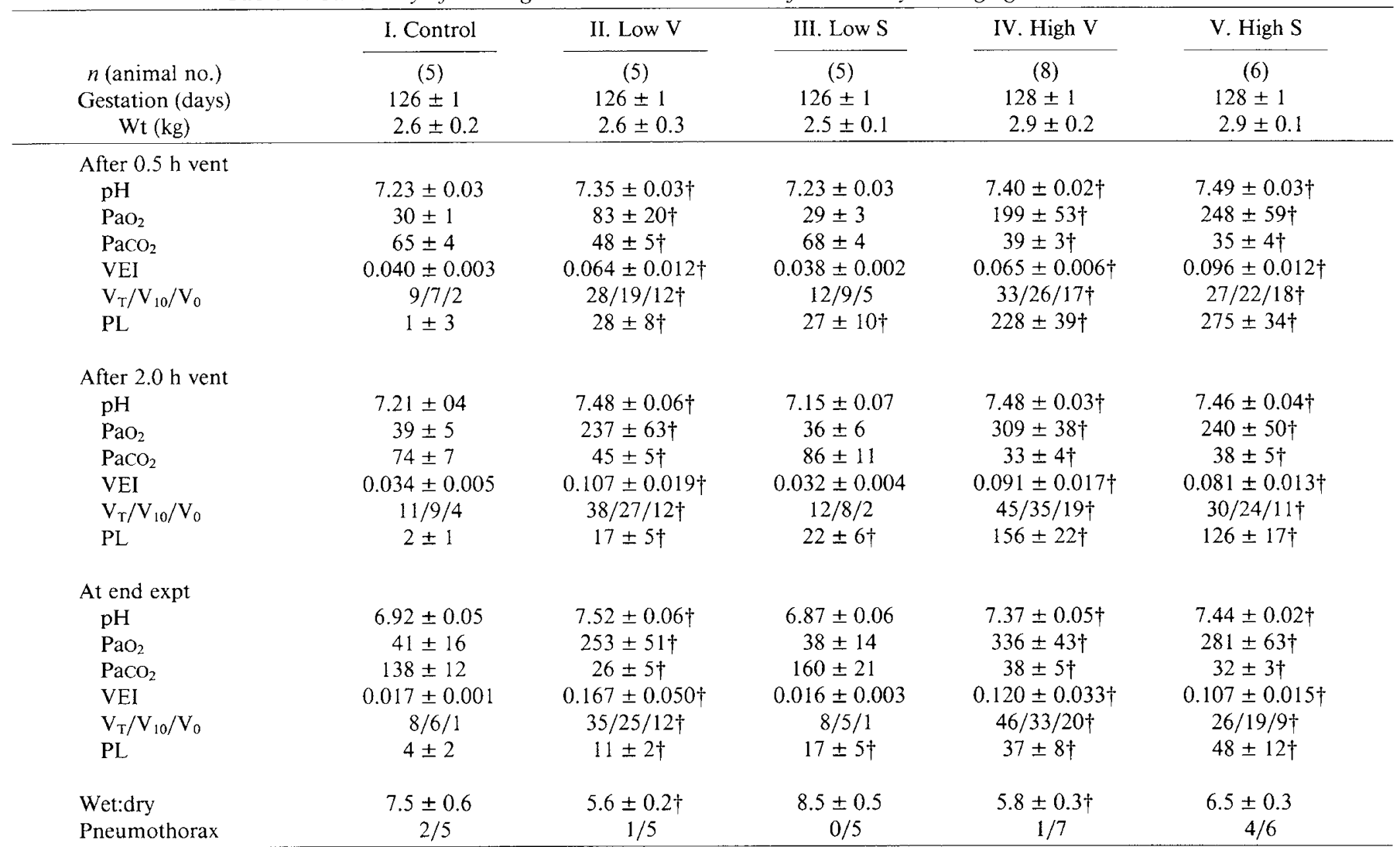

* Average values given as mean $\pm \mathrm{SEM} ; \mathrm{PaO}_{2}$ (torr) is on $100 \% \mathrm{O}_{2} ; \mathrm{PaCO}_{2}$ (torr); VEI is index of ventilatory efficiency defined in Equation (3); Volumes are $\mathrm{ml} / \mathrm{kg}$ animal weight at $35 \mathrm{~cm} \mathrm{H} \mathrm{H}_{2} \mathrm{O}\left(\mathrm{V}_{\mathrm{T}}\right), 10 \mathrm{~cm} \mathrm{H} \mathrm{H}_{2} \mathrm{O}\left(\mathrm{V}_{10}\right)$, and $0 \mathrm{~cm} \mathrm{H}_{2} \mathrm{O}\left(\mathrm{V}_{0}\right.$, equivalent to functional residual capacity) above atmospheric pressure. Alveolar phospholipid (PL) is given in total micromoles per lung; the amount of surfactant (CLL) instilled initially was 15 $\mathrm{mg} / \mathrm{kg}$ for low $\mathrm{V}$ and low $\mathrm{S}$, and $100 \mathrm{mg} / \mathrm{kg}$ for high $\mathrm{V}$ and high S. Time of experiment end was variable, with a maximum of $12 \mathrm{~h}$; animals found to have pneumothoracies on autopsy, for a given group number, are denoted at the bottom of each column, along with the average wet/dry weight ratio for animal lungs in each group.

$\dagger$ Statistically significant $(p<0.05$ or less) compared to corresponding control group value. 
Table 2. Summary of physiological data for 133-day gestation lambs*

\begin{tabular}{|c|c|c|c|c|}
\hline & I. Control & II. Low S & III. High S & $\begin{array}{l}\text { IV. High } \\
\mathrm{V}\end{array}$ \\
\hline$n$ (animal no.) & (5) & (5) & (4) & $(2)$ \\
\hline Gestation (days) & $133 \pm 1$ & $133 \pm 1$ & $133 \pm 1$ & 133 \\
\hline $\mathrm{Wt}(\mathrm{kg})$ & $3.4 \pm 0.3$ & $2.9 \pm 0.2$ & $2.4 \pm 0.2$ & 2.7 \\
\hline \multicolumn{5}{|l|}{ After $0.5 \mathrm{~h}$ vent } \\
\hline $\mathrm{pH}$ & $7.36 \pm 0.03$ & $7.45 \pm 0.02 \dagger$ & $7.50 \pm 0.03 \dagger$ & $7.40 \dagger$ \\
\hline $\mathrm{PaO}_{2}$ & $81 \pm 17$ & $212 \pm 78 \dagger$ & $349 \pm 71 \dagger$ & 401 \\
\hline $\mathrm{PaCO}_{2}$ & $45 \pm 3$ & $33 \pm 2 \dagger$ & $34 \pm 5 \dagger$ & 39 \\
\hline VEI & $0.058 \pm 0.004$ & $0.079 \pm 0.006 \dagger$ & $0.079 \pm 0.006 \dagger$ & 0.078 \\
\hline $\mathrm{V}_{\Upsilon} / \mathrm{V}_{10} / \mathrm{V}_{0}$ & $24 / 18 / 9$ & $31 / 22 / 13$ & $45 / 35 / 21 \dagger$ & $44 / 36 / 18$ \\
\hline $\mathrm{PL}$ & $16 \pm 8$ & $41 \pm 11 \dagger$ & $199 \pm 44 \dagger$ & 179 \\
\hline $\mathrm{pH}$ & $7.44 \pm 0.05$ & $7.44 \pm 0.02$ & $7.55 \pm 0.04$ & 7.57 \\
\hline $\mathrm{PaO}_{2}$ & $217 \pm 59$ & $97 \pm 21$ & $482 \pm 16 \dagger$ & 404 \\
\hline $\mathrm{PaCO}_{2}$ & $38 \pm 5$ & $34 \pm 2$ & $28 \pm 4 \dagger$ & 37 \\
\hline VEI & $0.083 \pm 0.019$ & $0.086 \pm 0.010$ & $0.137 \pm 0.031 \dagger$ & 0.091 \\
\hline $\mathrm{V}_{\mathrm{T}} / \mathrm{V}_{10} / \mathrm{V}_{0}$ & $35 / 25 / 10$ & $35 / 25 / 13$ & $57 / 45 / 20 \dagger$ & $67 / 52 / 20$ \\
\hline $\mathrm{PL}$ & $5 \pm 1$ & $24 \pm 11 \dagger$ & $97 \pm 13 \dagger$ & 83 \\
\hline \multicolumn{5}{|l|}{ At end expt } \\
\hline $\mathrm{pH}$ & $7.38 \pm 0.05$ & $7.33 \pm 0.07$ & $7.50 \pm 0.06$ & 7.41 \\
\hline $\mathrm{PaO}_{2}$ & $249 \pm 65$ & $218 \pm 82$ & $370 \pm 30$ & 432 \\
\hline $\mathrm{PaCO}_{2}$ & $35 \pm 4$ & $42 \pm 7$ & $33 \pm 5$ & 25 \\
\hline VEI & $0.100 \pm 0.027$ & $0.052 \pm 0.025$ & $0.33 \pm 0.07 \dagger$ & 0.43 \\
\hline $\mathrm{V}_{\mathrm{T}} / \mathrm{V}_{10} / \mathrm{V}_{0}$ & $32 / 23 / 10$ & $43 / 28 / 13$ & $45 / 34 / 19 \dagger$ & $61 / 47 / 19$ \\
\hline $\mathrm{PL}$ & $23 \pm 7$ & $13 \pm 4$ & $21 \pm 6$ & 23 \\
\hline Wet/dry & $5.8 \pm 0.1$ & $6.8 \pm 0.7$ & $5.6 \pm 0.1$ & 6.0 \\
\hline Pneumothorax & $0 / 5$ & $2 / 5$ & $1 / 4$ & $0 / 2$ \\
\hline
\end{tabular}

* All values mean \pm SEM. All details as in Table 1 legend. No SEM for high dose CLL(V) since $n=2$.

$\dagger$ Statistically significant ( $p<0.05$ or less) compared to corresponding control group value.

4) Alveolar phospholipid content in treated lambs was increased over controls at $0.5 \mathrm{~h}$ of ventilation by an amount close to that instilled initially (low or high dose, sonicated or vortexed). Phospholipid content then steadily decreased as each experiment progressed, although it was still significantly above control levels when experiments were terminated at or before $12 \mathrm{~h}$. However, CLL(V) and CLL(S) groups were equivalent in alveolar phospholipid at a given dose and time. They were not distinguishable on this biochemical basis, in contrast to their different behavior in terms of lung function and mechanics.

The segregation of the various groups of 127-day average gestation lambs as responders [low and high dose CLL(V) and high dose CLL(S)] and nonresponders [low dose CLL(S), equivalent to controls] is shown clearly in Figure 1, which gives the P. $\mathrm{V}$ deflation curves for the various groups. This is also shown in Figure 2 which compares the VEI in equation (3), and the value of $\mathrm{A}-\mathrm{a} \mathrm{DO}_{2}$, among the five groups of lambs.

The overall pattern of differences between the groups of lambs (Table 1; Figs. 1 and 2) was also reflected in experiments on twin lambs. Figure 3 shows blood gas and VEI results for a 126-day twin experiment which compared the effects of instillation of low doses $(15 \mathrm{mg} / \mathrm{kg})$ of CLL(V) and CLL(S). The animal given low dose CLL(S) in Figure 3 had lung function parameters equivalent to control lambs. However, the low dose CLL(V) treated twin showed greatly improved blood oxygenation and a high VEI (improved dynamic compliance). In addition, the CLL(V) twin had increased functional residual capacity and quasistatic P-V compliance compared to its twin and to control lambs (not shown explicitly on Fig. 3).

Figure 4 shows a twin experiment which compared the effects of instillation of high dose (100 mg/kg) CLL(V) and CLL(S). In contrast to the large difference in physiological efficacy seen at lower dose, the data of Figure 4 show that instillation of a large
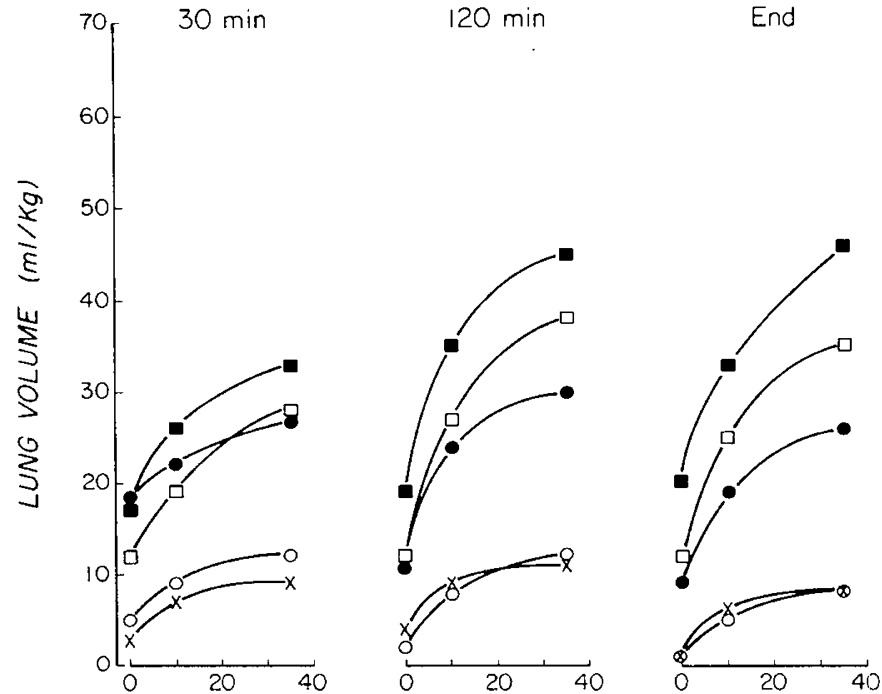

PRESSURE $\left(\mathrm{cm} \mathrm{H}_{2} \mathrm{O}\right)$

Fig. 1. Quasistatic P-V deflation curves for 127-day average gestation lambs in Table 1. X, control group I; $\square, \mathrm{CLL}(\mathrm{V})$ low dose group II; $\mathrm{O}$, CLL(S) low dose group III; $\boldsymbol{\square}, \mathrm{CLL}(\mathrm{V})$ high dose group IV; $\bullet$ CLL(S) high dose group $\mathrm{V}$.

enough dose of CLL(S) can improve lung function to a similar level as found with $\operatorname{CLL}(\mathrm{V})$. This dose-response behavior is replicated in the concentration-dependent activity of CLL(S) and CLL(V) in surfactant-deficient excised lungs as discussed later.

Physiological results, 133-day gestation lambs. Sixteen lambs of average gestational age 133 days were studied to determine if 

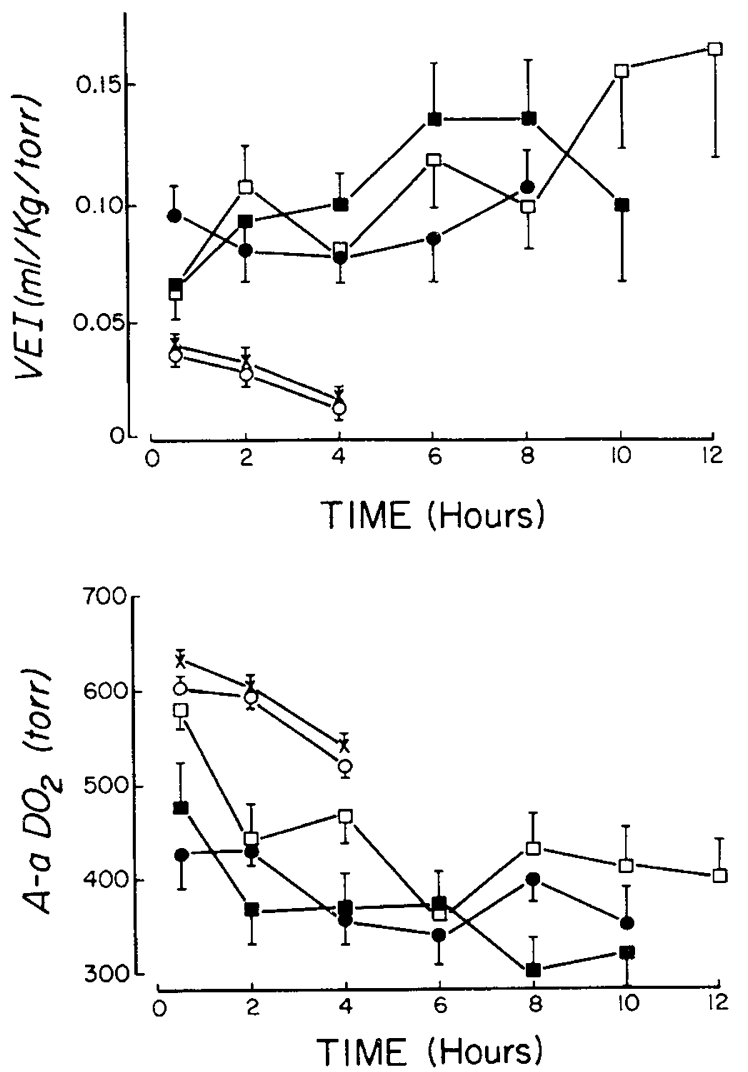

Fig. 2. VEI [equation (3)] and A-a $\mathrm{DO}_{2}$ for 127-day average gestation lambs. Same notation as in Figure 1.

CLL(S) had a similar dose-dependent efficacy in more mature animals. The CLL(S) groups were compared to control animals and to two animals given a high dose of CLL(V).

Table 2 gives a summary of the blood gas and lung mechanical data from these 133-day animals, and Figures 5 and 6 show results for $\mathrm{P}-\mathrm{V}$ deflation behavior, ventilatory efficiency, and Aa $\mathrm{DO}_{2}$. These data demonstrate that the dose-response effect for CLL(S) seen with younger lambs is still present. Instillation of low doses $(15 \mathrm{mg} / \mathrm{kg})$ of CLL(S) in 133-day gestation lambs did not significantly enhance lung function over controls. However, when high doses $(100 \mathrm{mg} / \mathrm{kg})$ of CLL(S) were instilled, animal response was a dramatic improvement in pulmonary function, quite close to that found with instillation of CLL(V) dispersions. The alveolar phospholipid content measurements for 133-day animals in Table 2 also parallel the results found for 126 day fetuses in Table 1.

Surface property results. The three surface properties that are considered most important for lung surfactant function in vivo are dynamic surface tension lowering, respreading, and adsorption (eg, Reference 4). These variables were investigated for CLL(V) and CLL(S) dispersions in a series of biophysical studies.

The $\pi$-time adsorption isotherms found for CLL(S) and CLL(V) are shown in Figure 7; each is a representative curve closely reproduced in at least five separate experiments. These data show that CLL dispersed by sonication on ice exhibits rapid interfacial adsorption (in seconds) to surface pressures of about 45 dynes/cm for final subphase concentrations of $0.06 \mathrm{mg}$ phospholipid per milliliter; this behavior is in agreement with the $\pi$ time adsorption data found previously for other CLL(S) preparations (8). The results in Figure 7 also show that vortexed CLL dispersions adsorb to the same final surface pressure as in the sonicated case. The adsorption of CLL(V) at a subphase concentration of $0.06 \mathrm{mg} / \mathrm{ml}$ is slower than for CLL(S), and there is a point of inflection in the $\pi$-time adsorption isotherm. However, if subphase phospholipid concentration is increased to $0.25 \mathrm{mg} /$
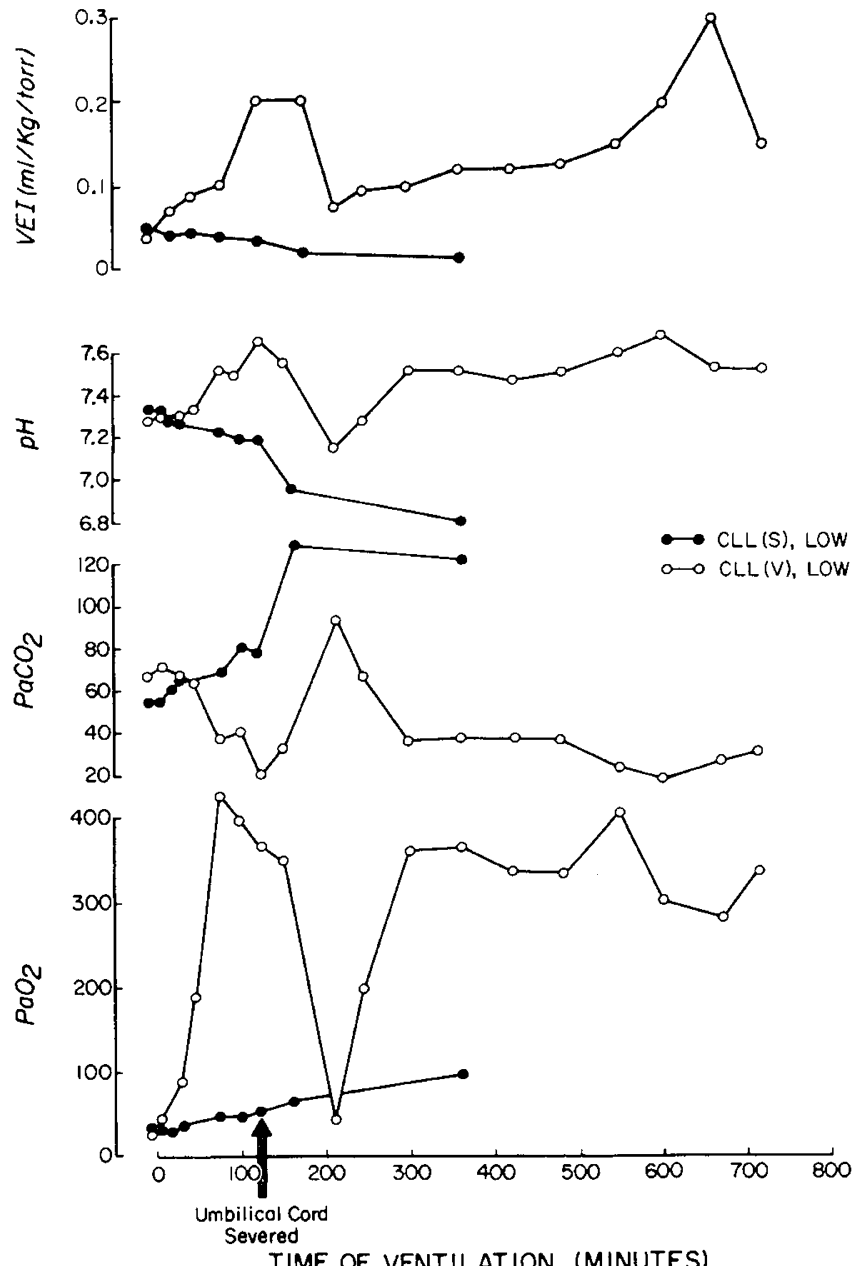

Fig. 3. Arterial blood gas measurements for 126-day twins given $\mathrm{V}$ and S lipids at low dose $(15 \mathrm{mg} / \mathrm{kg})$. Fetus A, $2.22 \mathrm{~kg}$, group III treated with sonicated lipids (---); fetus B, $1.90 \mathrm{~kg}$, in group II treated with vortexed lipids (O---O). See text for details.

$\mathrm{ml}$, the adsorption of vortexed dispersions is as rapid as that found for sonicated dispersions (curve B compared to curve A in Fig. 7). This CLL concentration was exceeded in all lamb experiments based on measurements of lung liquid volume and the known amount of phospholipid instilled.

The surface tension lowering characteristics of CLL films under dynamic compression conditions were investigated by two techniques: a Wilhelmy surface balance and an oscillating bubble. Egan et al. (17) have previously demonstrated that solventspread CLL films can lower surface tension to $\leq 1 \mathrm{dyne} / \mathrm{cm}$ on dynamic compression in a Wilhelmy balance, with good dynamic respreading shown by a collapse plateau ratio (cycle 2 /cycle 1 ) of about 0.9 (at $22^{\circ} \mathrm{C}$, initial concentration $10 \AA^{2} / \mathrm{mol}$ ). Essentially identical Wilhelmy balance results were found for the CLL preparations used in the present study. These surface balance data, however, are for CLL films spread directly at the air-water interface from an organic solvent in which the lipids are soluble, and thus do not reflect effects from dispersion of CLL in an aqueous bulk phase. Wilhelmy balance results for solvent-spread CLL films only show that if these lipids are present in sufficient concentration at the air-water interface, they can lower surface tension effectively.

A dynamic surface tension lowering technique that includes direct consideration of phospholipid dispersions is the oscillating bubble (30), which measures a combination of dynamic surface tension lowering, respreading, and adsorption facility. In our bubble experiments, CLL were dispersed by sonication or vor- 

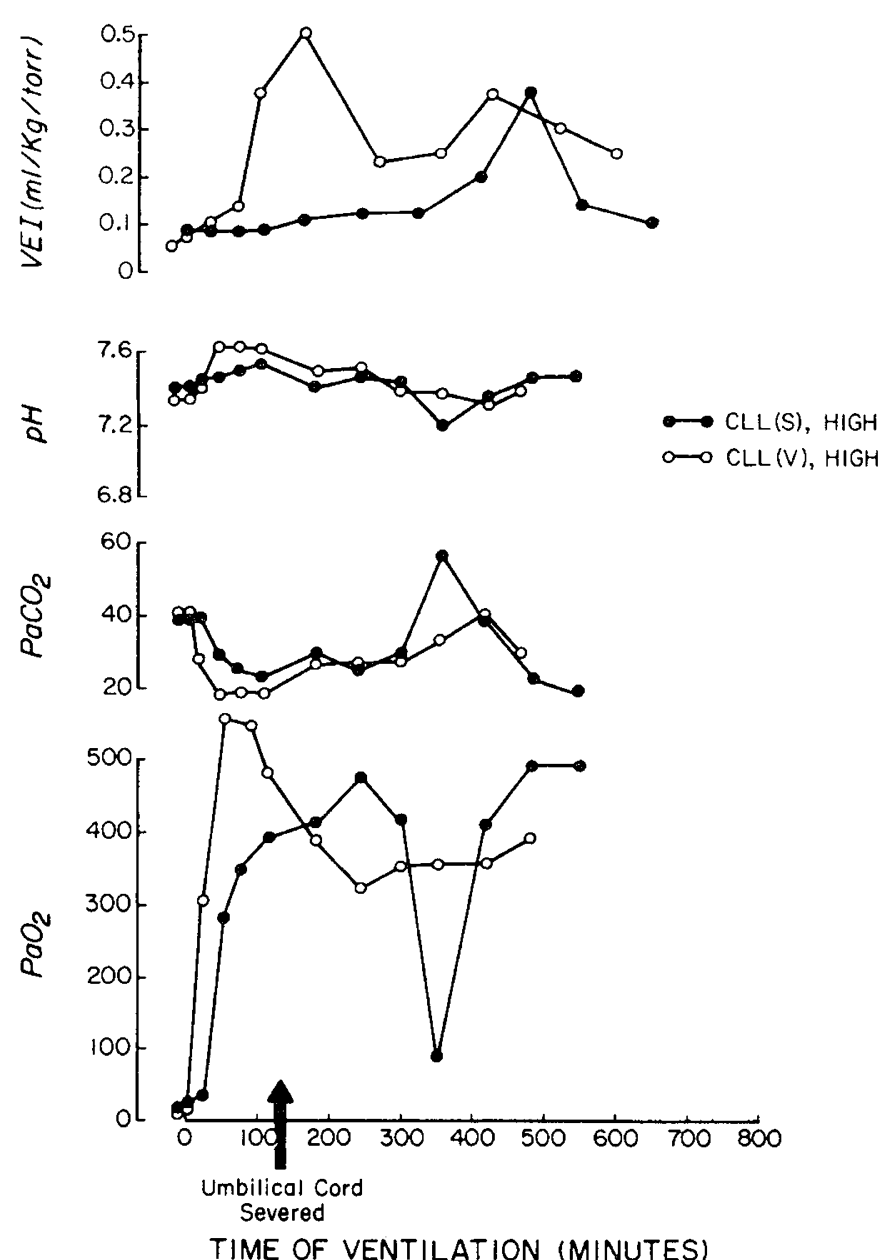

Fig. 4. Arterial blood gas data for 130-day twins given high dose (100 $\mathrm{mg} / \mathrm{kg}$ ) $\mathrm{V}$ and $\mathrm{S}$ lipids. Fetus $\mathrm{A}$ in group $\mathrm{V}$ treated with $100 \mathrm{mg} / \mathrm{kg} \mathrm{S}$ CLL (-.-@); twin fetus B treated with same dose of V CLL ( $\left({ }_{-. .} \mathrm{O}\right)$. See text for details.

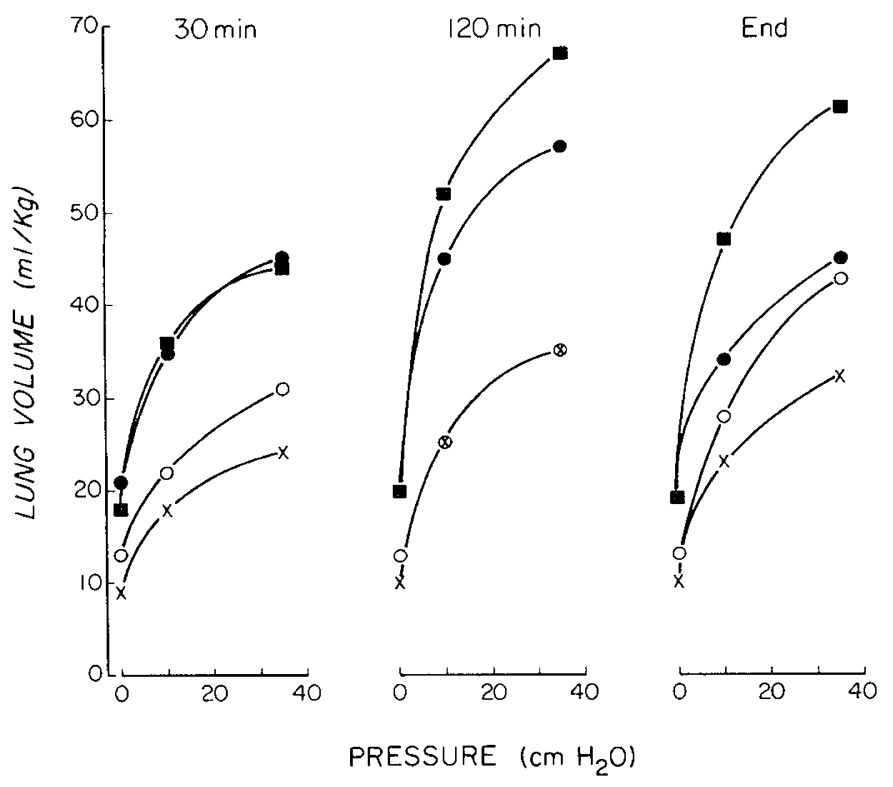

Fig. 5. Quasistatic P-V deflation curves for 133-day average gestation lambs in Table 2. $\times$, control group I; O, CLL(S) low dose group II; CLL(S) high dose group III; $\mathbf{E}, \mathrm{CLL}(\mathrm{V})$ high dose group IV.
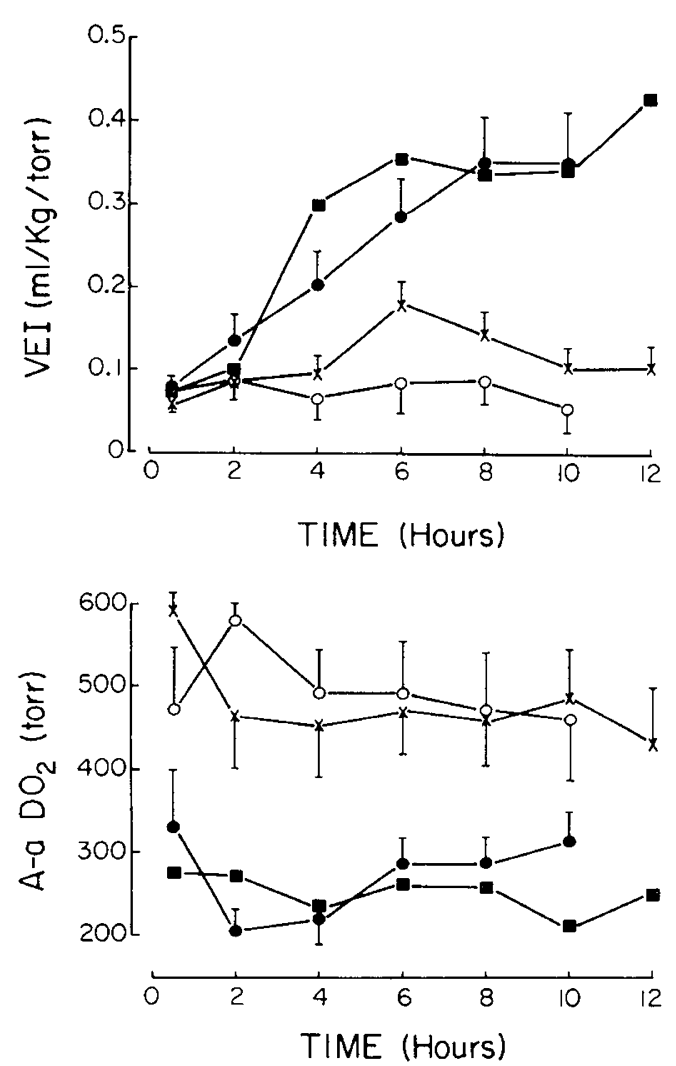

Fig. 6. VEI and $\mathrm{A}-\mathrm{a} \mathrm{DO}_{2}$ for 133-day average gestation lambs in Table 2. Same notation as in Figure 5.

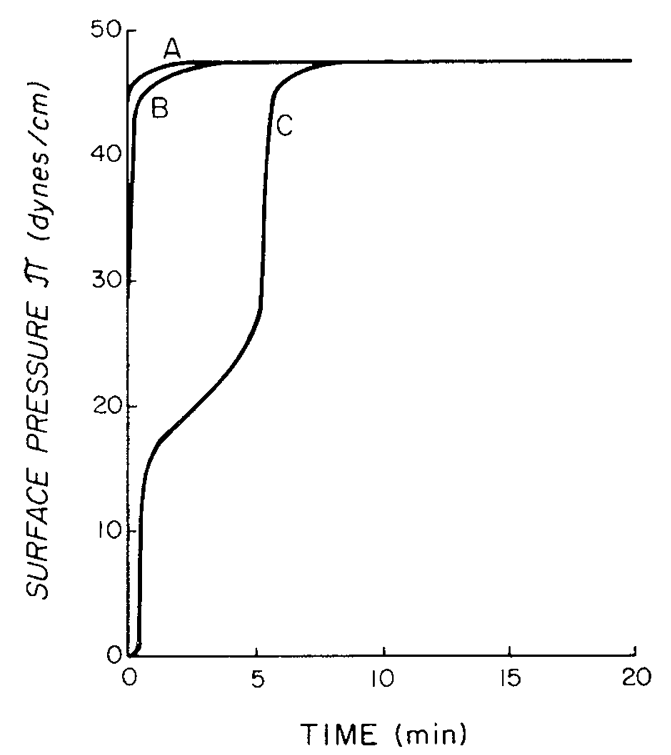

Fig. 7. $\pi$-Time adsorption of CLL dispersions by $\mathrm{V}$ and $\mathrm{S}$. Curves shown are representative isotherms. $A, \mathrm{CLL}(\mathrm{S})$ at bulk dispersion concentration $0.06 \mathrm{mg} / \mathrm{ml} ; B, \mathrm{CLL}(\mathrm{V})$ at $0.25 \mathrm{mg} / \mathrm{ml} ; C, \mathrm{CLL}(\mathrm{V})$ at 0.06 $\mathrm{mg} / \mathrm{ml}$.

texing at concentrations 5,1 , and $0.5 \mathrm{mg} / \mathrm{ml}$, and surface properties were measured at 20 cycles per minute at $37^{\circ} \mathrm{C}$ with a compression ratio (maximum area/minimum area) of $2 / 1$. At these conditions, both CLL(V) and CLL(S) gave minimum surface tension values approaching 0 dynes $/ \mathrm{cm}$ and maximum surface tension values of 31-34 dynes/cm.

Although the magnitude of the final minimum surface tension generated by CLL(V) and CLL(S) was uniform, the time required 
to reach this minimum value after bubble pulsation was begun depended on dispersion concentration. At 5 and $1 \mathrm{mg} \mathrm{CLL} / \mathrm{ml}$, both vortexed and sonicated dispersions gave surface tension values $<2$ dyne/cm in equivalent times (within 2 min at $5 \mathrm{mg}$ / $\mathrm{ml}$ and within $4 \mathrm{~min}$ at $1 \mathrm{mg} / \mathrm{ml}$ ). ${ }^{2}$ At $0.5 \mathrm{mg} \mathrm{CLL} / \mathrm{ml}$, vortexed dispersions took less time on average to reach this value than did sonicated dispersions [an average of $10 \pm 1$ (SEM) min for CLL(V) and $20 \pm 2 \mathrm{~min}$ for CLL(S) in six independent experiments for each dispersion type]. This concentration dependence of the time necessary to reach a minimum surface tension of $<2$ dyne $/ \mathrm{cm}$ in a pulsating bubble is not striking, but it is consistent with the physiological effects found for CLL(V) and CLL(S) dispersions in lambs in vivo. A more marked concentration dependence, which correlated directly with the lamb results, was found in measurements of the effects of CLL(V) and CLL(S) on $\mathrm{P}-\mathrm{V}$ mechanics in excised, surfactant-deficient rat lungs.

Excised lung mechanical results. Figure 8 shows the P-V characteristics of excised rat lungs at $37^{\circ} \mathrm{C}$ in the surfactantsufficient state (curve $A$ ) and the surfactant-deficient state generated by multiple saline lavages (curve $F$ ). Curves $B$ through $D$ show improved P-V mechanics after instillation of 25 and 17 $\mathrm{mg} / \mathrm{kg}$ rat weight of CLL(V) and CLL(S), respectively. The bars on the various curves represent $\pm S E$ at the given volume found in five independent experiments at each dose. Comparison of the appropriate curves in Figure 8 shows that CLL(V) restores pulmonary mechanics toward normal at lower concentrations than CLL(S). The differences between curves $B$ and $D$ and between $C$ and $E$ are statistically significant well below the $p=$ 0.05 level. This difference between the effects of CLL(V) and CLL(S) dispersions diminished as the total amount of instilled surfactant was increased above the values in Figure 8. At dose levels of $40 \mathrm{mg} / \mathrm{kg}$, the two types of dispersion were found to change P.V mechanics almost equally, to a curve just below $A$ on Figure 8 (data not shown explicitly). In general, these mechanical results directly parallel the physiological effects of CLL(V) and CLL(S) on lung function in lambs in Tables 1 and 2.

\section{DISCUSSION}

Our results show that preventilatory instillation of dispersions of CLL into the lungs of premature lambs produces significantly enhanced pulmonary function and mechanics over controls. A total of 45 animals was studied at two gestational ages, with widely separated dose levels (100 and $15 \mathrm{mg} / \mathrm{kg}$ ) and two different CLL dispersion methods. In the most effectively treated groups, those receiving $100 \mathrm{mg} C L L(V)$ per kilogram, lung volumes began to approach those reported for normal newborns (31). Beneficial pulmonary P-V mechanical changes which increased with dose were also found when CLL dispersions were tracheally instilled in excised, surfactant-deficient rat lungs.

In contrast to previous experiments in which natural lung surfactant was instilled in lambs after the onset of breathing (32), the beneficial effects of CLL were sustained for at least an 8 to 12 -h period of study provided that an effective dose was delivered. For CLL(V), beneficial effects were found in lambs at a low dose of $15 \mathrm{mg} / \mathrm{kg}$, but this was not true for CLL(S). Even for CLL(V), higher doses resulted in further improvements in P$\mathrm{V}$ mechanics in excised rat lung studies, and a trend toward further improvement in lambs. Our studies do not purport to define a complete dose-response relationship for either CLL(V) or CLL(S), but they do suggest that a dose of $100 \mathrm{mg} / \mathrm{kg}$ will be

${ }^{2}$ The numerical limit of 2 dynes/cm is arbitrarily chosen to avoid effects in calculations due to bubble deformation from a sphere, which can occur at very low surface tension in the pulsating bubble apparatus. The value of 2 dynes $/ \mathrm{cm}$ is clearly low enough to indicate a highly surface active dispersion. Moreover, microscopic observation of the pulsating bubble indicated minimal deformation at a pressure drop value consistent with this surface tension and the Law of Young and Laplace for a spherical interface. All CLL dispersions studied went on to give minimum surface tensions approaching 0 dynes $/ \mathrm{cm}$, although bubble deformation from a spherical shape was then apparent.

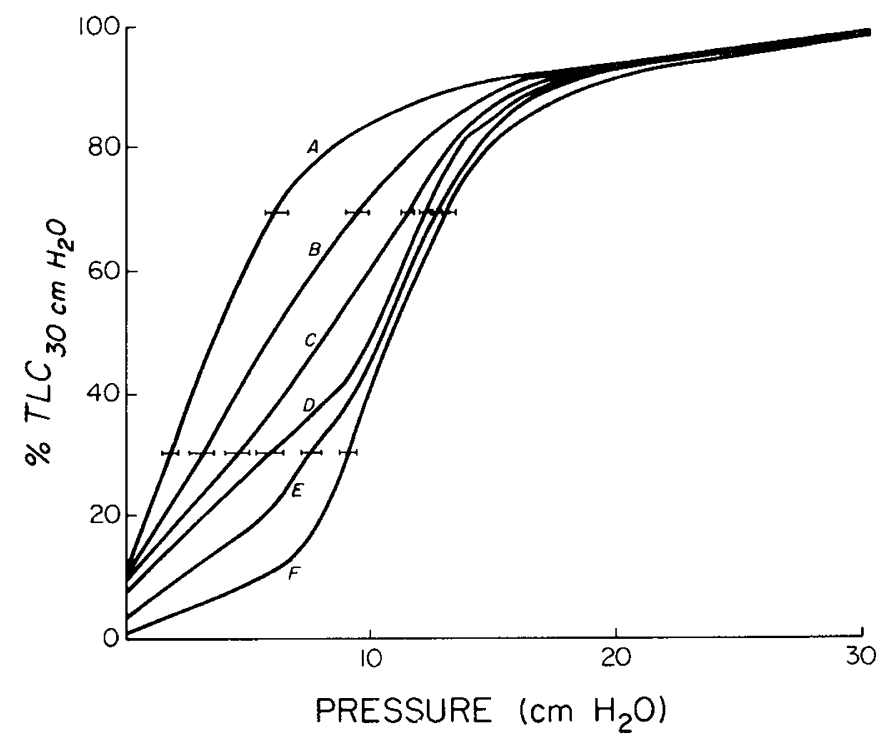

Fig. 8. VP deflation curves of excised, air-filled rat lungs following tracheal instillation of different doses of CLL dispersions. $A$, normal surfactant-sufficient lung; $B, 25 \mathrm{mg} / \mathrm{kg} \mathrm{CLL(V);} C, 17 \mathrm{mg} / \mathrm{kg}$ CLL(V); $D, 25 \mathrm{mg} / \mathrm{kg}$ CLL(S); $E, 17 \mathrm{mg} / \mathrm{kg}$ CLL(S); $F$, surfactant-deficient lung. Curve $F$ was obtained by multiple saline lavages prior to instillation of a surfactant dispersion. Each curve is the average of experiments in five animal lungs, with bars denoting SEM at 30 and $70 \%$ of total lung capacity. See text for details.

effective in reversing surfactant-deficiency in vivo. For this dose of CLL(V), observed effects in lambs were quantitatively greater than those reported previously for immature primates treated before breathing with natural rabbit surfactant (33).

Although the development of an effective synthetic surfactant with no protein remains an important goal, the effectiveness of CLL(V) in generating near normal respiratory function and P-V mechanics for many hours in premature sheep makes it a candidate for current therapy of neonatal RDS. This material contains almost an order of magnitude less protein (on a strictly quantitative basis) than natural surfactant from lung lavage or mincing (4-6), and thus has a reduced risk of immunogenicity. It is related to the surfactant extract preparation of Fujiwara and coworkers $(21-23,34)$ but does not require supplementation with any additives. Finally, it can be sterilized by flash autoclaving and retain physiological effectiveness in lambs (35). From such considerations, several medical centers in the United States and Canada have initiated clinical trials of exogenous surfactant replacement in RDS with CLL or closely related materials (36).

In terms of the effect of mixture dispersion technique on physiological efficacy, our results show that CLL(S) has a much more prominent dose dependence for effectiveness in vivo than CLL(V). However, prediction of this from in vitro biophysical studies alone was not straightforward. Measurements of the surface properties of adsorption, dynamic surface tension lowering, and dynamic respreading in vitro were used to characterize the two surfactant preparations. At low concentrations $(0.06 \mathrm{mg} /$ ml) CLL(S) actually adsorbed more rapidly than CLL(V), although this difference disappeared at concentrations below those instilled in surfactant replacement studies (Fig. 7). Oscillating bubble studies, which reflect a combination of all of these interfacial properties, showed slightly enhanced surface activity for CLL(V) over CLL(S) dispersions at low concentration. However, a more direct distinction between the two was found in their relative effects on pulmonary mechanics in the independent physiological model of surfactant-deficient, excised rat lungs. P$\mathrm{V}$ characteristics were restored more effectively by CLL(V) than CLL(S) dispersions at concentrations of 17 and $25 \mathrm{mg} / \mathrm{kg}$ (Fig. 8 ). This difference decreased when a large amount of phospho- 
lipid was instilled, a dependence which correlated well with the results of lamb studies in vivo.

Precise physicochemical mechanisms to explain the concentration dependent behavior of different types of CLL dispersions have not yet been defined. The surface activity of CLL(V) and CLL(S) dispersions is related, fundamentally, to the liposomes and other microstructural aggregates present. However, this microstructure has not been investigated in detail. Even if such data were available, they might not explain the intriguing finding that interfacial property variations between $\mathrm{CLL}(\mathrm{V})$ and $\mathrm{CLL}(\mathrm{S})$ were far less striking than the observed differences in physiological effects in excised lungs and in lambs. Regardless of underlying mechanism, the existence of variations in the physiological efficacy of exogenous surfactants depending on dispersion technique has pragmatic importance. Dispersion methodology is one more variable which needs to be controlled and studied in optimizing lung surfactant replacement therapy.

\section{REFERENCES}

1. Robertson B 1980 Surfactant substitution experimental models and clinical applications. Lung 158:57-68

2. Notter RH, Shapiro DL 1981 Lung surfactant in an era of replacement therapy. Pediatrics 68:781-789

3. Robertson B 1981 Neonatal pulmonary mechanics and morphology after experimental therapeutic regimens. In: Scarpelli EM (ed) Reviews in Perinatal Medicine, Vol 4. Raven Press, New York, pp 337-379

4. Robertson B, van Golde LMG, Batenburg JJ (eds) 1984 Pulmonary Surfactant Elsevier, Amsterdam

5. Sanders RL 1982 The chemical composition of the lung. In: Farrell PM (ed) Lung Development: Biological and Clinical Perspectives, Vol I, Biochemistry and Physiology. Academic Press, New York, pp 179-219

6. King RJ 1974 The surfactant system of the lung. Fed Proc 22:2238-2247

7. Notter RH, Morrow PE 1975 Pulmonary surfactant: a surface chemistry viewpoint. Ann Biomed Eng 3:119-159

8. Notter RH, Finkelstein JN, Taubold RD 1983 Comparative adsorption of natural lung surfactant, extracted phospholipids, and artificial phospholipid mixtures. Chem Phys Lipids 33:67-80

9. King RJ, Macbeth MC 1979 Physicochemical properties of dipalmitoyl phosphatidylcholine after interaction with an apolipoprotein of pulmonary surfactant. Biochim Biophys Acta 557:86-101

10. King RJ, Macbeth MC 1981 Interactions of the lipid and protein components of pulmonary surfactant: role of phosphatidylglycerol and calcium. Biochim Biophys Acta 647:159 168

11. Suzuki Y 1982 Effect of protein, cholesterol, and phosphatidylglycerol on the surface activity of the lipo-protein complex reconstituted from pig pulmonary surfactant. J Lipid Res 23:62-69

12. Magoon MW, Wright JR, Baritussio A, Williams MC, Goerke J, Benson BJ, Hamilton RL, Clements JA 1983 Subfractions of lung surfactant: implications for metabolism and surface activity. Biochim Biophys Acta 750:18-31

13. Benson BJ, Hawgood S, Williams MC 1984 Role of apoprotein and calcium ions in surfactant function. Exp Lung Res 6:223-236

14. Benson BJ, Williams MC, Sueishi K, Goerke J, Sargeant T 1984 Role of calcium ions in the structure and function of pulmonary surfactant. Biochim
Biophys Acta 793:18-27

15. Metcalfe IL, Enhorning G, Possmayer F 1980 Pulmonary surfactant associated proteins: their role in the expression of surface activity. J Appl Physiol 49:34-41

16. Notter RH, Smith S, Taubold RD, Finkelstein NJ 1982 Path dependence of adsorption behavior of mixtures containing dipalmitoyl phosphatidylcholine. Pediatr Res 16:515-519

17. Egan EA, Notter RH, Kwong MS, Shapiro DL 1983 Natural and artificial lung, surfactant replacement in premature lambs. J Appl Physiol 55:875-883

18. Yu S, Harding PGR, Smith N, Possmayer F 1983 Bovine pulmonary surfactant: chemical composition and physical properties. Lipids 18:522-529

19. Bermel MS, McBride JT, Notter RH 1984 Lavaged excised rat lungs as a model of surfactant deficiency. Lung 162:99-113

20. Metcalfe IL, Pototschnik R, Burgoyne R, Enhorning G 1982 Lung expansion and survival in rabbit neonates treated with surfactant extract. J Appl Physiol 53:838-843

21. Fujiwara T, Tanaka Y, Takei T 1979 Surface properties of artificial surfactant in comparison with natural and synthetic surfactant lipids. ICRS Med Sci 7:311(abstr)

22. Fujiwara T Maeta H, Chida S, Morita T 1979 Improved pulmonary pressurevolume characteristics in premature newborn rabbits after tracheal instillation of artificial surfactant. IRCS Med Sci 7:312(abstr)

23. Fujiwara T 1984 Surfactant replacement in neonatal RDS. In: Robertson B, van Golde LMG, Batenburg JJ (eds) Pulmonary Surfactant. Elsevier, Amsterdam, pp 479-503

24. Bligh EG, Dyer WJ 1959 A rapid method of total lipid extraction and purification. Can J Biochem Physiol 37:911-917

25. Chen PS Jr, Toribara TY, Huber W 1956 Microdetermination of phosphorus. Anal Chem 28:1756-1758

26. Touchstone JC, Chen JC, Beaver KM 1980 Improved separation of phospholipids in thin layer chromatography. Lipids 15:61-62

27. Lowry OH, Rosebrough NJ, Farr AL, Randall RJ 1951 Protein measurement with the folin phenol reagent. J Biol Chem 132:265-275

28. Clements JA, Platzker AC, Tierney DF, Hobel CG, Creasy RK, Margolis AJ, Thiebeault DW, Fooley WH, Oh W 1972 Assessment of the risk of respiratory distress syndrome by a rapid test for surfactant in amniotic fluid. $\mathrm{N}$ Engl J Med 286:1077-1081

29. Comroe JH, Forster RE, DuBois AB, Brisco WA, Carlsen E 1962 The Lung, 2nd ed. Year Book Medical Publishers, Chicago, IL, pp 339-341

30. Enhorning G 1977 Pulsating bubble technique for evaluating pulmonary surfactant. J Appl Physiol 43:198-203

31. Krauss AN 1979 Ventilation-perfusion relationships in neonates. In: Thibeault DW, Gregory GA (eds) Neonatal Pulmonary Care. Addison-Wesley, MenloPark, CA, pp 54-69

32. Jobe A, Ikegami M, Glatz $T$, Yoshida $Y$, Diakomanolis, Padbury J 198 Duration and characterization of treatment of premature lambs with natural surfactant. J Clin Invest 67:370-375

33. Enhorning G, Hill D, Sherwood G, Cutz E, Robertson B, Bryan C 1973 Improved ventilation of prematurely delivered primates following trachea deposition of surfactant. Am J Obstet Gynecol 132:529-536

34. Fujiwara T, Maeta H, Chida S, Morita T, Watabe Y, Abe T 1980 Artificial surfactant therapy in hyaline membrane disease. Lancet 1:55-59

35. Kwong MS, Egan EA, Shapiro DL, Notter RH 1984 Effectiveness of extracted cow lung lipids in inducing and sustaining normal lung function in premature lambs. Pediatr Res 18:395(abstr)

36. Proceedings of the Ross Laboratories Special Conference: Clinical trials of the use of surfactant in the neonatal respiratory distress syndrome, Washington, DC, November 29-December 1, 1984, Professional Services Department, Ross Laboratories, Columbus, OH, pp 12-36 